033

\title{
FARINGOTONSILLITE CAUSATA DA ARCANOBACTERIUM HAEMOLYTICUM. DUE CASI CLINICI
}

\author{
Usai F., Carluccio AV., Cocco ME., Burgio A., Saddi B., \\ Laboratorio Analisi, Ospedale SS. Trinità, Cagliari
}

Introduzione. Arcanobacterium haemolyticum è un bastoncello Gram-positivo, asporigeno, anaerobio facoltativo, immobile, catalasi negativo. È causa di faringotonsilliti, non di rado accompagnate da esantema; ma può ritrovarsi come componente della normale flora faringea in soggetti sani. Sono riportati due casi clinici.

Caso clinico 1. Paziente di 27 anni, di sesso maschile, fumatore. Il paziente riferiva la comparsa, nel maggio 2004, di un episodio di faringotonsillite, con ingrossamento delle tonsille, placche di essudato biancastro, e febbre fino a $39^{\circ} \mathrm{C}$. Una terapia empirica con amoxicillina + ac. clavulanico (AMC) conduceva solo ad una parziale remissione della sintomatologia, cui seguiva una recrudescenza della faringotonsillite. L'esame colturale di un tampone faringeo eseguito nel nostro Laboratorio nel giugno 2004, portava all'isolamento di $A$. haemolyticum, in carica predominante rispetto al resto della flora faringea. Il trattamento con claritromicina, dava luogo ad una completa risoluzione delle manifestazioni cliniche.

Caso clinico 2. Paziente di 22 anni, di sesso maschile, fumatore. Il paziente riferiva la presenza di una faringotonsillite febbrile, recidivante nonostante i ripetuti trattamenti con AMC. Nel luglio 2004, la ricerca mirata di A. haemolyticum nella coltura di un tampone faringeo, portava all'isolamento del microrganismo, in carica discreta nel contesto di una normale flora faringea. I valori di ASLO risultavano nella norma. La terapia con claritromicina, conduceva alla completa risoluzione del quadro clinico, senza ulteriore comparsa di nuove recidive.

Metodi e Risultati. L'isolamento dei due ceppi in esame di A. haemolyticum è stato ottenuto su agar CNA con sangue di montone, incubato in aerobiosi a $37^{\circ} \mathrm{C}$, per $24-48 \mathrm{~h}$. L'identificazione a livello di specie è stata eseguita con la galleria Api Coryne, dopo positività al reverse-CAMP test. Entrambi gli isolati sono risultati sensibili ad AMC e claritromicina, ma resistenti a levofloxacina e cotrimoxazolo.

Discussione. I due casi clinici sopra esposti, suggeriscono che, in caso di faringotonsillite, la ricerca di A. haemolyticum deve essere eseguita in modo mirato, una volta escluso il coinvolgimento dei più comuni agenti patogeni delle alte vie respiratorie. Tuttavia, poiché la beta-emolisi non è sempre visibile, il reverse-CAMP test potrebbe essere utile per eseguire uno screening delle colonie sospette. Le penicilline possono risultare inefficaci nel trattamento delle infezioni da A. haemolyticum, nonostante la sensibilità in vitro; i macrolidi sono pertanto da preferire. 